\title{
Identification of Dopaminergic Neurons of Nigral and Ventral Tegmental Area Subtypes in Grafts of Fetal Ventral Mesencephalon Based on Cell Morphology, Protein Expression, and Efferent Projections
}

\author{
Lachlan Thompson, Perrine Barraud, Elin Andersson, Deniz Kirik, and Anders Björklund \\ Wallenberg Neuroscience Center, Department of Experimental Medical Research, and Lund Strategic Center for Stem Cell Biology and Cell Therapy, Lund \\ University, SE-221 84 Lund, Sweden
}

\begin{abstract}
Transplants of fetal ventral mesencephalic tissue are known to contain a mixture of two major dopamine (DA) neuron types: the A9 neurons of the substantia nigra pars compacta $(\mathrm{SNpc})$ and the $\mathrm{A} 10$ neurons of the ventral tegmental area (VTA). Previous studies have suggested that these two DA neuron types may differ in their growth characteristics, but, because of technical limitations, it has so far been difficult to identify the two subtypes in fetal ventral mesencephalon (VM) grafts and trace their axonal projections. Here, we have made use of a transgenic mouse expressing green fluorescent protein (GFP) under the tyrosine hydroxylase promoter. The expression of the GFP reporter allowed for visualization of the grafted DA neurons and their axonal projections within the host brain. We show that the SNpc and VTA neuron subtypes in VM grafts can be identified on the basis of their morphology and location within the graft, and their expression of a G-protein-gated inwardly rectifying $\mathrm{K}^{+}$channel subunit (Girk2) and calbindin, respectively, and also that the axonal projections of the two DA neuron types are markedly different. By retrograde axonal tracing, we show that dopaminergic innervation of the striatum is derived almost exclusively from the Girk2-positive SNpc cells, whereas the calbindin-positive VTA neurons project to the frontal cortex and probably also other forebrain areas. The results suggest the presence of axon guidance and target recognition mechanisms in the DA-denervated forebrain that can guide the growing axons to their appropriate targets and indicate that cell preparations used for cell replacement in Parkinson's disease will be therapeutically useful only if they contain cells capable of generating the correct nigral DA neuron phenotype.
\end{abstract}

Key words: tyrosine hydroxylase; green fluorescent protein; GFP; calbindin; Girk2; Parkinson's disease; transplantation

\section{Introduction}

Cell replacement Parkinson's disease (PD) is based on the idea that the grafted cells can replace the lost endogenous dopamine (DA) neurons. Previous studies have shown that this may be possible to achieve using fetal DA neuroblasts, provided that the grafted DA neurons can establish a new functional DA innervation of the denervated striatum (Winkler et al., 2000). This property is not shared by all DA neuroblasts: only cells derived from the ventral mesencephalon (VM) that innervate the striatum are able to establish an extensive terminal network in the host stria-

\footnotetext{
Received April 27, 2005; revised May 30, 2005; accepted June 2, 2005.

This work was supported by grants from the Swedish Research Council and the EuroStemCell program grant from the European Commission. The Lund Stem Cell Center is supported by a Center of Excellence Grant from the Swedish Foundation for Strategic Research. L.T. was supported by grants from the European Commission (DANCE project) and the Wenner-Gren Foundation. We thank Ulla Jarl, Anneli Josefsson, Elsy Ling, and Bengt Mattsson for technical assistance. We thank Drs. Hideyuki Okano and Kazuto Kobayashi for providing the TH-GFP mice and Dr. Ole Isacson for valuable advice in the design of this study and the suggestion to use the Girk2 antibody for nigral cell identification.

Correspondence should be addressed to Lachlan Thompson, Wallenberg Neuroscience Center, Division of Neurobiology, Lund University, BMC A11, S-221 84 Lund, Sweden. E-mail: lachlan.thompson@mphy.lu.se.

D0I:10.1523/JNEUROSCI.1676-05.2005

Copyright $\odot 2005$ Society for Neuroscience $\quad$ 0270-6474/05/256467-11\$15.00/0
}

tum. DA neuroblasts taken from other developing brain regions do not share this property (Abrous et al., 1988; Zuddas et al., 1991; Hudson et al., 1994).

The cells used for DA neuron replacement in PD may thus have to be of the correct phenotype. The DA neuroblasts contained in the developing VM, however, are not a homogenous population but comprise two major subtypes: the neurons of the substantia nigra pars compacta (SNpc) [A9 neurons; Dahlstrom and Fuxe (1964)], which give rise to the nigrostriatal pathway; and the A10 neurons of the ventral tegmental area (VTA), which give rise to the mesolimbic and mesocortical pathways that innervate and parts of the limbic system and the neocortex (Bjorklund and Lindvall, 1984). Previous studies have suggested that these two neuron phenotypes may possess different growth characteristics and that only neurons of the nigral A9 subtype are able to reinnervate the denervated striatum after transplantation (Schultzberg et al., 1984; Haque et al., 1997; Bjorklund and Isacson, 2002). However, because of technical limitations, it has so far been difficult to trace the axonal projections of these two tyrosine hydroxylase-positive $\left(\mathrm{TH}^{+}\right)$cell types in VM grafts with any degree of certainty.

Here we used a transgenic reporter mouse (Sawamoto et al., 
2001) as a source of fetal VM tissue for transplantation, in which green fluorescent protein (GFP) is expressed under the TH promoter (TH-GFP). Because the GFP protein is expressed not only in the cell bodies but also in all of processes, this allows selective visualization of the grafted DA neurons and their axonal projections within the host brain. To distinguish the two principal DA neuron subtypes, the VTA and the SNpc cells, we used antibodies recognizing the calcium binding protein calbindin, which is expressed in the vast majority of the $\mathrm{TH}^{+}$A10 neurons (Rogers, 1992; Liang et al., 1996; McRitchie et al., 1996; Damier et al., 1999; Mendez et al., 2005), and the G-proteingated inwardly rectifying $\mathrm{K}^{+}$channel Girk2, which in the midbrain is expressed almost exclusively in the $\mathrm{TH}^{+}$A9 neurons (Schein et al., 1998; Inanobe et al., 1999; Mendez et al., 2005). The results show that the SNpc and VTA neurons in VM grafts can be identified on the basis of their Girk2 and calbindin expression, as well as their cellular morphology and localization within the grafts. We show, moreover, that the innervation of the striatum is derived from the grafted SNpc cells, whereas the VTA cells project to extrastriatal forebrain areas.

\section{Materials and Methods}

Adult (200-250 g) or neonatal (postnatal day 1-3) Sprague Dawley rats were used as graft recipients in these experiments and were housed on a $12 \mathrm{~h}$ light/dark cycle with ad libitum access to food and water. All procedures were conducted in accordance with guidelines set by the Ethical Committee for the use of laboratory animals at Lund University.

\section{VM cell suspensions}

Timed pregnant mice [day of vaginal plug was designated embryonic day 0.5 (E0.5)] were generated by crossing wild-type (wt), NMRI females with heterozygous transgenic, C57BL/6 males expressing GFP under the control of the TH promoter (Sawamoto et al., 2001). At E12.5, embryos were removed from pregnant mothers after lethal exposure to $\mathrm{CO}_{2}$, and the $\mathrm{GFP}^{+/-}$and wt littermates were identified and separated under a fluorescence microscope, before storing on ice in L-15 buffer (Invitrogen, Gaithersburg, MD). The VM was dissected free from each embryo as described previously (Dunnett and Björklund, 1992, 2000), taking care to remove the meninges. Pooled GFP ${ }^{+-}$(or in some cases wt) VM tissue from 25-35 embryos in each of three dissection sessions was mechanically dissociated in PBS without $\mathrm{Ca}^{2+}$ or $\mathrm{Mg}^{2+}\left(\mathrm{PBS}^{-\mathrm{Ca} 2+/ \mathrm{Mg} 2+}, 0.1 \mathrm{M}\right.$; Invitrogen). The number of viable cells was estimated based on tryptan blue (Sigma, St. Louis, MO) exclusion, and, after centrifugation $(500 \times g$, $5 \mathrm{~min}, 4^{\circ} \mathrm{C}$ ), the supernatant was removed and the volume was adjusted to give a suspension of $1.0 \times 10^{5}$ viable cells/ $\mu \mathrm{l}$ in $\mathrm{HBSS}^{-\mathrm{Ca} 2+/ \mathrm{Mg} 2+}$ (Invitrogen). The cells were stored on ice during the transplantation procedure.

\section{6-OHDA lesions and transplantation}

Adults. Female Sprague Dawley rats received unilateral injections of 6-OHDA ( $3 \mu \mathrm{g} / \mu \mathrm{l}$ free base dissolved in $0.9 \% \mathrm{w} / \mathrm{v} \mathrm{NaCl}$ with $0.2 \mathrm{mg} / \mathrm{ml}$ $\mathrm{L}$-ascorbic acid) into the right medial forebrain bundle at two sites using G-I, $50 \mu \mathrm{m}$.
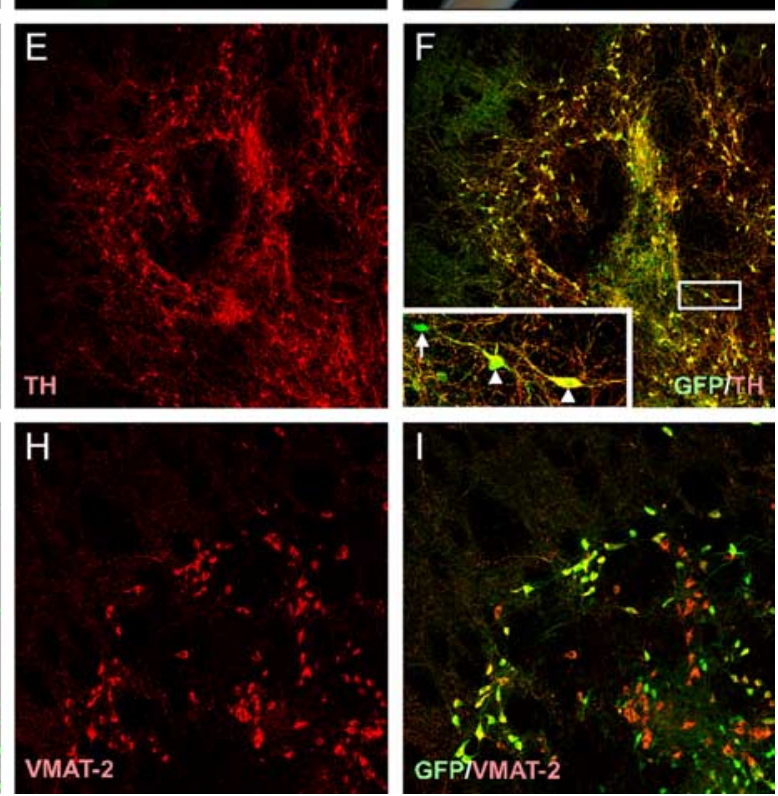

VMAT-2
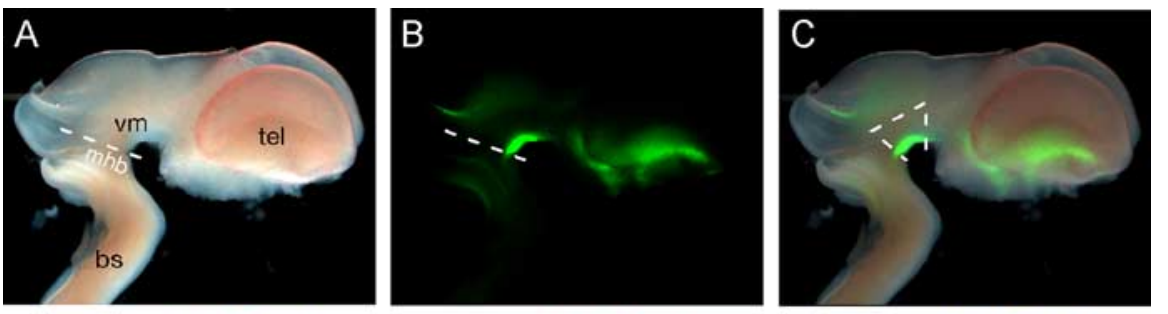

Figure 1. Expression of the GFP reporter in dopaminergic neurons. Bright-field $(\boldsymbol{A})$, native GFP fluorescence $(\boldsymbol{B})$, and a merge of these panels ( $($ ) from an E12.5 TH-GFP transgenic mouse brain. The GFP signal can clearly be seen in the VM and to a lesser degree (D) and TH (E) 6 cenceks an. The white lines in C indicate the region dissected for transplantation. Immunohistochemistry for GFP cells also express $\mathrm{TH}\left(\boldsymbol{F}\right.$; merged image). The few $\mathrm{GFP}^{+} / \mathrm{TH}^{-}$cells observed had an immature morphology and lacked dendritic processes (inset from boxed area in $\boldsymbol{F}$, arrow; arrowheads indicate GFP ${ }^{+} / \mathrm{TH}^{+}$cells). The dopaminergic nature of GFP ${ }^{+}$cells was also assessed through immunohistochemistry for VMAT-2 $(\mathbf{G}-\boldsymbol{I})$. The VMAT ${ }^{+} / \mathrm{GFP}^{-}$cells (red cells in $\boldsymbol{I}$ ) represent serotonergic neurons. bs, Brainstem; mhb, mid-hindbrain boundary; tel, telencephalon; vm, ventral mesencephalon. Scale bars: D-F, $200 \mu \mathrm{m}$;

a stereotaxic apparatus (Stoelting, Wiesenbach, Germany) and $10 \mu \mathrm{l}$ Hamilton syringe $(2.5 \mu \mathrm{l}$ at $4.4 \mathrm{~mm}$ caudal and $1.2 \mathrm{~mm}$ lateral to bregma, $7.8 \mathrm{~mm}$ below the dural surface, tooth bar set at $-2.4 \mathrm{~mm} ; 3 \mu \mathrm{l}$ at $4.0 \mathrm{~mm}$ caudal and $0.8 \mathrm{~mm}$ lateral to bregma, $8.0 \mathrm{~mm}$ below dura, tooth bar set at $+3.4 \mathrm{~mm}$ ). Three weeks later, the animals were challenged with D-amphetamine $(2.5 \mathrm{mg} / \mathrm{kg})$, and animals displaying rotational asymmetry of $\geq 6$ turns/min (mean over $90 \mathrm{~min}$ ) were selected for transplantation. All transplantation procedures were based on a microtransplantation protocol using glass capillaries attached to a $5 \mu$ l Hamilton syringe, as described previously (Nikkhah et al., 2000). Six weeks later, lesioned or intact adult rats were placed in a flat-skull position and received a unilateral, $2 \mu \mathrm{l}$ injection of GFP ${ }^{+/-}$VM cells $\left(1.0 \times 10^{5}\right.$ cells $\left./ \mu \mathrm{l}\right)$ into the right striatum. An initial deposit of $1 \mu \mathrm{l}$ was made at $0.5 \mathrm{~mm}$ anterior and $3.0 \mathrm{~mm}$ lateral to bregma, $5.5 \mathrm{~mm}$ below the dural surface. The capillary was left in place for $2 \mathrm{~min}$ before depositing another $1 \mu \mathrm{l}$ along the same capillary tract, $4.5 \mathrm{~mm}$ below the dura, and withdrawing the capillary after an additional 3 min delay. The survival time for these animals was 6 weeks from the day of transplantation. Immunosuppressive treatment was administered for this period in the form of daily intraperitoneal injections of cyclosporin A (15 mg/kg; Novartis, Basel, Switzerland) beginning on the day of surgery.

Neonates. For all neonatal surgical procedures, a miniature stereotaxic stage (Stoelting) fitted to a stereotaxic frame was used (Nikkhah et al., 2000). Hypothermic anesthesia was induced by placing the pups in ice for $5 \mathrm{~min}$ and maintained by periodically adding dry ice to absolute ethanol in a reservoir built into the stereotaxic stage. Postnatal day 1 (P1) rats 

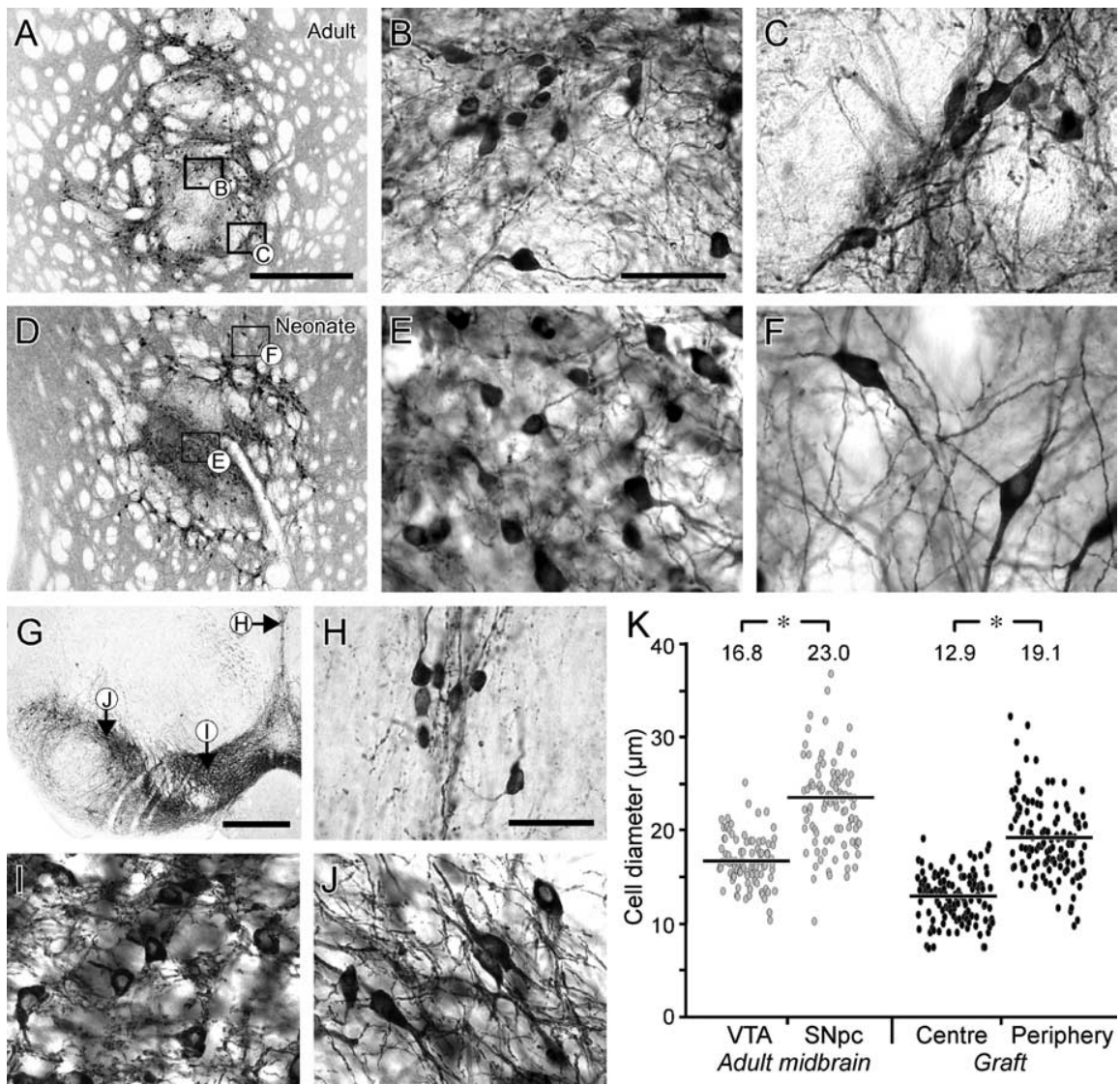

Figure 2. Differential distribution of dopaminergic neuron subtypes in VM grafts and substantia nigra based on morphology $\boldsymbol{A}-\boldsymbol{F}$, Six weeks after transplantation to the adult $(\boldsymbol{A})$ or neonatal $(\boldsymbol{D})$ striatum, GFP-immunopositive cells could be found in both central and peripheral locations within the graft core. Cells within the center of the graft $(\boldsymbol{B}, \boldsymbol{E})$ were rounded and significantly smaller, on average, than the more elongated and angular cells in the periphery $(\boldsymbol{C}, \boldsymbol{F}), \mathbf{G}-\boldsymbol{J}$, In the adult mouse mesencephalon $(G)$, the $\mathrm{TH}^{+}$neurons in the VTA $(\boldsymbol{I})$, including those along the midline $(\boldsymbol{H})$, are characteristically smaller and more rounded in shape compared with the larger and more angular $\mathrm{TH}^{+}$cells within the $\mathrm{SNpc}(J)$. The scatter plots in $K$ give the diameters of GFP ${ }^{+}$ cells in different regions of VM grafts placed in 6-OHDA-lesioned adults (filled circles) and $\mathrm{TH}^{+}$cells in the intact mouse VTA and $\mathrm{SNpc}$ (open circles). The more medial/central cells were significantly smaller than those positioned more laterally/peripherally. The average cell diameters (indicated at the top of each group) differed significantly: Student's $t$ test, ${ }^{*} p<0.01 ; n=92$ (VTA), $n=93$ (SNpc), and $n=124$ (center and periphery). Scale bars: $\boldsymbol{A}, \boldsymbol{D}, 500 \mu \mathrm{m} ; \boldsymbol{B}, \boldsymbol{C}, \boldsymbol{E}, \boldsymbol{F}, \boldsymbol{H}-\boldsymbol{J}, 50 \mu \mathrm{m} ; \boldsymbol{G}, 1 \mathrm{~mm}$.

received unilateral injections of 6-OHDA $(5 \mu \mathrm{l} ; 10 \mu \mathrm{g} / \mu \mathrm{l})$ into the right lateral ventricle over a period of $2 \mathrm{~min}$ using a glass capillary attached to the tip of a $5 \mu \mathrm{l}$ Hamilton syringe $(0.5 \mathrm{~mm}$ anterior and $1.1 \mathrm{~mm}$ lateral to bregma, $2.5 \mathrm{~mm}$ below the dura). Two days later, lesioned or intact P3 neonates received a $1 \mu$ injection of either $\mathrm{GFP}^{+/-}$or wt VM cells $(1.0 \times$ $10^{5}$ cells $\left./ \mu \mathrm{l}\right)$ into the right striatum $(0.7 \mathrm{~mm}$ anterior and $1.9 \mathrm{~mm}$ lateral to bregma, $2.9 \mathrm{~mm}$ below the dura). Cells were injected over $2 \mathrm{~min}$, and the capillary was left in place for an additional 3 min before withdrawal. Survival time for these animals was 6 weeks.

\section{Retrograde tracing}

Cholera toxin subunit $\beta$ (CTB) prelabeled with an Alexa-555 fluorophore $(0.1 \% \mathrm{w} / \mathrm{v}$ in $0.9 \%$ saline; Molecular Probes, Eugene, OR) was used to retrogradely label grafted cells in 6-week-old animals that had previously received 6-OHDA lesions and VM cell grafts as neonates. The CTB was injected using a glass capillary (as described above) into either the right frontal cortex ( $1 \mu$ l over $2 \mathrm{~min} ; 2.7 \mathrm{~mm}$ anterior and $1.0 \mathrm{~mm}$ lateral to bregma, $2.0 \mathrm{~mm}$ below the dura) or the right dorsolateral striatum $(0.2$ $\mu$ lover $1 \mathrm{~min} ; 1.2 \mathrm{~mm}$ posterior and $4.1 \mathrm{~mm}$ lateral to bregma, $3.5 \mathrm{~mm}$ below the dura). The survival time was $7 \mathrm{~d}$ from the day of CTB injection.

\section{Tissue processing and immunohistochemistry}

All animals were transcardially perfused with $50 \mathrm{ml}$ of saline $(0.9 \% \mathrm{w} / \mathrm{v})$, followed by $200 \mathrm{ml}$ ice-cold paraformaldehyde (PFA) $(4 \% \mathrm{w} / \mathrm{v}$ in $0.1 \mathrm{M}$ PBS). The brains were removed, postfixed for $2 \mathrm{~h}$ in $4 \%$ PFA, and cryo- protected overnight in sucrose $(25 \% \mathrm{w} / \mathrm{v}$ in 0.1 M PBS) before being sectioned on a freezing microtome (Leica, Nussloch, Germany). Coronal sections were collected in 12 series at a thickness of $30 \mu \mathrm{m}$.

Immunohistochemical (IHC) procedures were performed according to the same basic protocol. Free-floating sections were washed in $0.1 \mathrm{~m}$ potassium PBS (KPBS) three times before application of the primary antibody, and washes with KPBS were performed between each step in the IHC protocol. When appropriate, endogenous peroxidase activity was quenched for 15 min with $3 \% \mathrm{H}_{2} \mathrm{O}_{2}$. Primary antibodies were diluted in KPBS with $0.25 \%$ Triton X-100 (KPBS-Triton; Amresco, Solon, $\mathrm{OH}$ ) and $5 \%$ normal serum from the same species from which the secondary antibody was derived. Diluted primary antibody mixture was applied overnight at room temperature. Secondary antibodies were diluted in KPBS-Triton with $2 \%$ normal serum from the same species and applied for $2 \mathrm{~h}$. For peroxidase-based reactions, a biotinylated secondary was used followed by incubation with streptavidin-horseradish peroxidase complex ( $\mathrm{ABC}$ Elite kit, Vectastain; Vector Laboratories, Burlingame, $\mathrm{CA}$ ) for $1 \mathrm{~h}$. The material was then exposed to di-amino-benzidine $(0.5 \mathrm{mg} / \mathrm{ml}$; Sigma), and precipitation of the chromophore was catalyzed by the addition of $1 \% \mathrm{H}_{2} \mathrm{O}_{2}$, followed by final washing in KPBS. The free-floating sections were mounted on gelatinized slides and dehydrated in alcohol and xylene before being coverslipped with DePeX mounting media (BDH Chemicals, Poole, UK). For labeling of multiple antigens in the same material, primary antibodies were prepared as described above and applied to the material followed by concurrent application of secondary antibodies with directly conjugated fluorophores. In some cases, signal amplification was achieved by using a biotinylated secondary antibody, followed by incubation with a streptavidin-conjugated fluorophore. Slide-mounted material labeled with fluorescent antibodies was coverslipped with polyvinyl alcohol-1,4diazabicyclo[2.2.2] octane (Peterson, 1999). Primary antibodies and dilution factors were as follows: mouse anti-calbindin (1:1000; Sigma), chicken anti-GFP (1:5000; Chemicon, Temecula, CA), rabbit anti-GFP (1:20,000; Abcam, Cambridge, MA), rabbit anti-Girk2 (1:80; Alomone Labs, Jerusalem, Israel), mouse anti-TH (1:4000; Chemicon), and rabbit anti-TH (1:1000; Pel-Freez Biologicals, Rogers, AR). Secondary antibodies were as follows: biotinylated goat anti-rabbit; FITC- or cyanine 2 (Cy2)-conjugated donkey anti-chicken, donkey anti-mouse or streptavidin; Cy3-conjugated donkey anti-rabbit or streptavidin; and Cy5conjugated donkey anti-mouse or donkey anti-rabbit (all 1:200; Jackson ImmunoResearch, West Grove, PA).

\section{Quantification and statistical analysis}

The volume occupied by the VM graft core and the associated fiber innervation in the host striatum was estimated through extrapolation of the area quantified in every 12th tissue section processed for GFP IHC according to Cavalieri's principle (Cavalieri, 1966). This was achieved using an Olympus Optical (Ballerup, Denmark) BH2-RFCA microscope and CAST (Olympus Optical) stereology software. The volume occupied by the graft core was delineated by the outer perimeter of $\mathrm{GFP}^{+}$cells, and the area of striatal fiber innervation was delineated by the perimeter of $\mathrm{GFP}^{+}$fibers and was inclusive of the graft core itself. A total of 10 grafts were quantified in both intact $(n=5)$ and lesioned $(n=5)$ adult hosts, 
and the areas were compared between the two groups using Student's $t$ test with a value of 0.05 set as the limit for statistical significance.

The same stereology setup was used to quantify $\mathrm{TH}^{+}$cell diameters in intact, adult mice brains and $\mathrm{GFP}^{+}$cell diameters in the VM grafts. For each region quantified, the longest diameter of a given cell was recorded, and at least 30 cells were measured. Measurements recorded for each region were pooled from four grafts from lesioned adult hosts and from three intact mice. Average cell diameters between groups were compared using Student's $t$ test ( $p<0.05$ for statistical significance).

The number of $\mathrm{GFP}^{+}$cells in intact and lesioned adults was estimated through extrapolation of the number of $\mathrm{GFP}^{+}$cells counted in every 12 th coronal section for each animal. The method of Abercrombie (1946) was used to correct for double counting caused by cells spanning more than one section.

To accurately assess the percentage of GFP cells that coexpress $\mathrm{TH}$ after transplantation, random visual fields from seven grafts immunohistochemically labeled for GFP and TH were sampled using confocal microscopy (Leica DMRE). Recordings from intact and lesioned hosts were pooled, because there was no significant difference between these groups. Care was taken to sample only within the penetration range of the TH antibody $(\sim 12 \mu \mathrm{m}$ from each surface). A minimum of $100 \mathrm{GFP}$ cells were counted per graft. The same procedure was used to assess the percentage of $\mathrm{GFP}^{+}$ cells that coexpressed calbindin, Girk2, or both proteins, in grafts immunohistochemically labeled for these markers, with the exception that the visual fields sampled were selected from either the periphery or the center of the grafts and grouped accordingly for statistical analysis. A comparison of the Girk2 and calbindin expression in $\mathrm{GFP}^{+}$cells from either the center or periphery of the grafts was made using Student's $t$ test $(p<0.05$ for statistical significance).

\section{Imaging and schematics}

The macroscopic, fluorescence image of an embryonic TH-GFP brain illustrated in Figure 1 was acquired using a dissection microscope (Leica) equipped with a digital camera (Progress). Confocal images (see Figs. $1 D-I, 2,4,5,7,8$ ) were acquired using a Leica DMRE laser-scanning microscope equipped with green helium/neon, helium/neon, and argon lasers.

To provide low-magnification overviews of graft-derived fiber innervation throughout the host brain, fiber patterns were accurately traced (Canvas version 9.0.4; Deneba Systems, Miami, FL) over digital photomontages from coronal sections immunohistochemically labeled with GFP.

\section{Results}

GFP is expressed in the developing VM and in grafted dopaminergic neurons derived from the TH-GFP reporter mouse

The TH-GFP transgenic mouse used here has been described previously by Sawamoto et al. (2001). Consistent with this report,
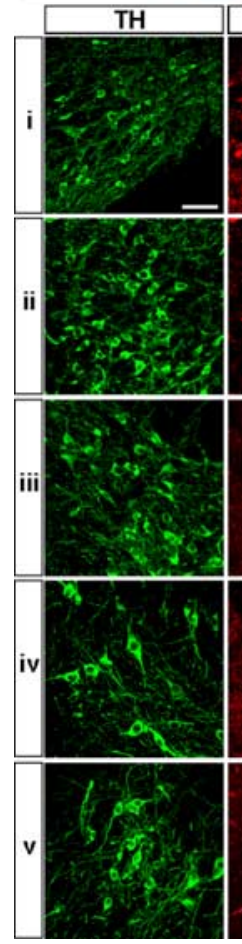
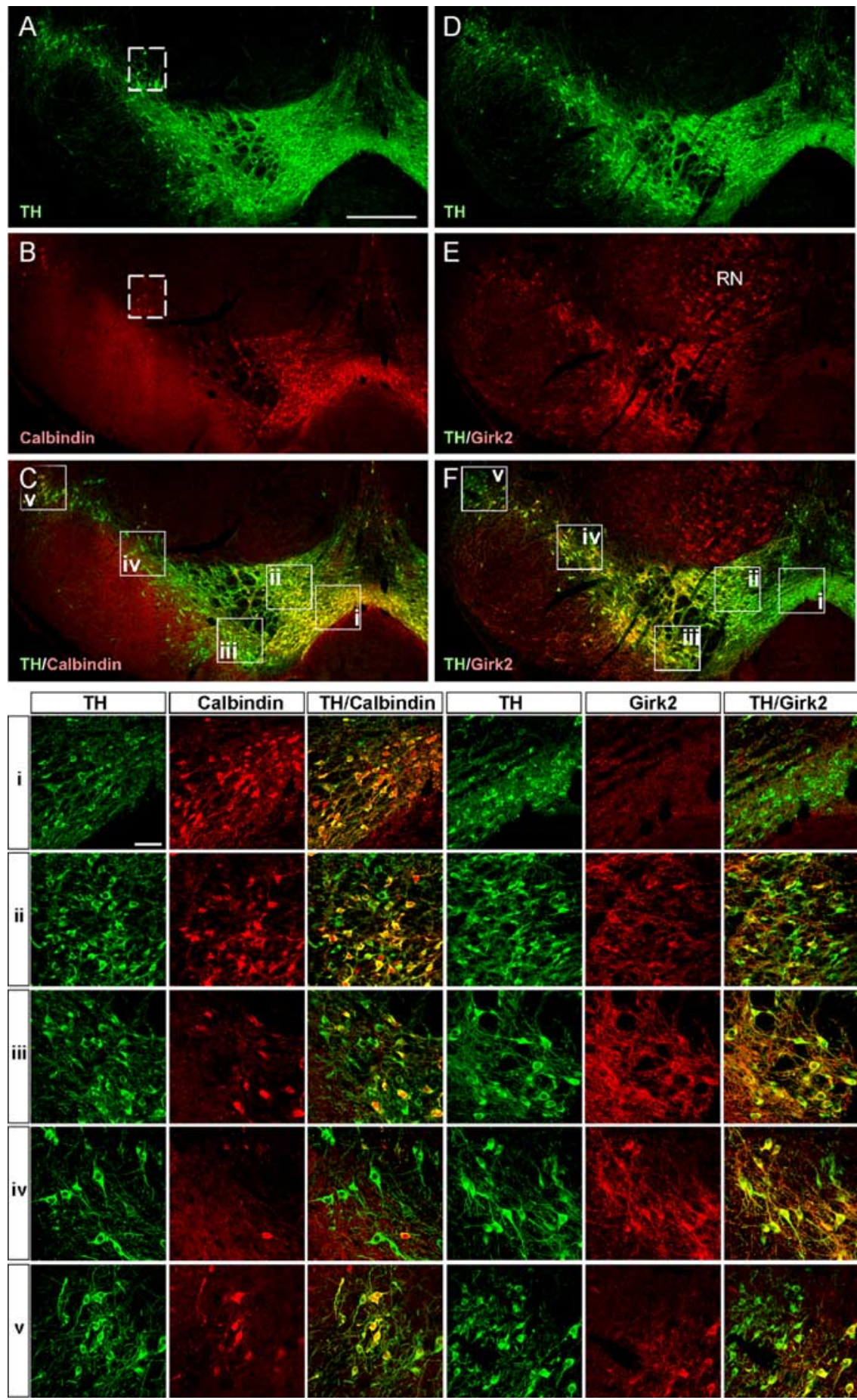

Figure 3. Calbindin and Girk2 expression in dopaminergic neurons in the adult mouse mesencephalon. Confocal images show the distribution of calbindin $(\boldsymbol{A}-\boldsymbol{C})$ and Girk2 $(\boldsymbol{D}-\boldsymbol{E})$ expressing cells within dopaminergic neurons of the substantia nigra from an adult mouse. Note that the calbindin $(\boldsymbol{B})$ and Girk2 $(\boldsymbol{C})$ expression domains appear distinctly nonoverlapping: calbindin is expressed predominately in the VTA and also in SN pars lateralis $(\boldsymbol{C})$, whereas Girk2 expression is primarily restricted to the $\operatorname{SNpc}(\boldsymbol{F})$ $\boldsymbol{i}-\boldsymbol{v}$, High-magnification images showing the expression of calbindin and Girk2 within $\mathrm{TH}^{+}$neurons of the VTA $(\boldsymbol{i}, \boldsymbol{i} i), \operatorname{SNpc}(i i i, \boldsymbol{i v})$, and $S N$ pars lateralis $(\boldsymbol{v})$. The positions from which these images were taken are indicated by boxed areas in $\boldsymbol{C}$ and $\boldsymbol{F}$. The dashed-boxed areas in $\boldsymbol{A}$ and $\boldsymbol{B}$ denote a small group of calbindin ${ }^{+} / \mathrm{TH}^{+}$cells consistently seen in a dorsal region of the SNpc. Calbindin and Girk2 expression are not restricted to dopaminergic neurons and are found in many $\mathrm{TH}^{-}$cells throughout the brain: note, for example, the prominent Girk2 expression in the red nucleus (RN). Scale bars: $A-F, 500 \mu \mathrm{m} ; \boldsymbol{i}-\boldsymbol{v}, 50 \mu \mathrm{m}$.

we observed a prominent GFP signal within the developing (E12.5) ventral midbrain and also, to a lesser extent, in a restricted area within the ventral telencephalon (Fig. $1 A-C$ ). In the adult mouse, the vast majority of $\mathrm{GFP}^{+}$cells within the midbrain 

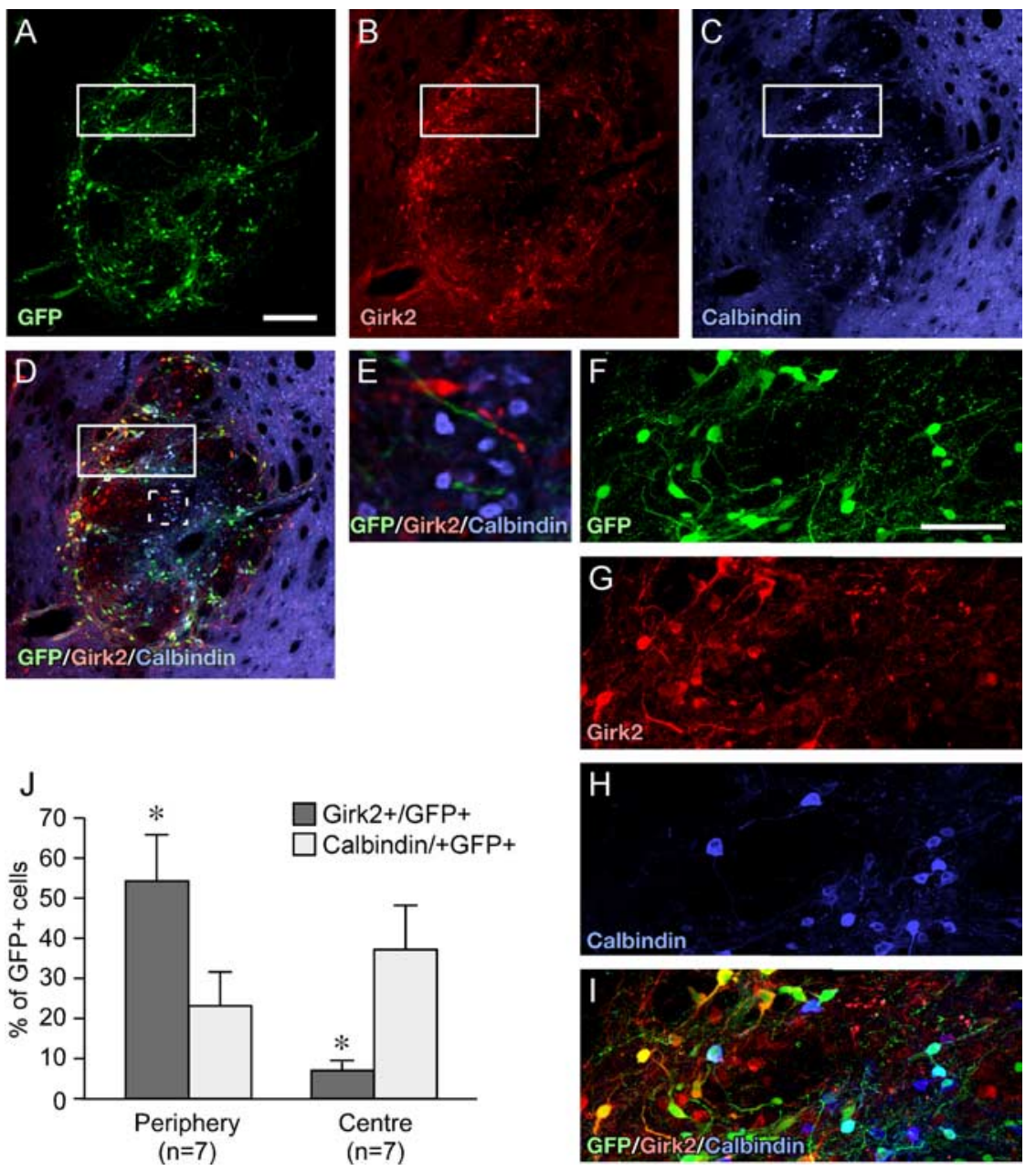

Figure 4. Calbindin and Girk2 expression in dopaminergic cells of VM grafts. Confocal immunohistochemistry for GFP $(\boldsymbol{A})$, Girk2 $(\boldsymbol{B})$, and calbindin $(\boldsymbol{C})$. Six weeks after transplantation into intact or 6-0HDA-lesioned adult rats, all VM grafts contained GFP ${ }^{+}$ neurons expressing Girk2 or calbindin (D). The example shown here is from an intact adult recipient. Girk2/GFP coexpressing cells were positioned predominately in the periphery of the graft, whereas the calbindin/GFP coexpressing cells were located mainly in the center. The boxed areas in $\boldsymbol{A}-\boldsymbol{D}$ incorporate a peripheral and more central aspect of the graft and are shown at higher magnification $(\boldsymbol{F}-\boldsymbol{I})$. As is the case in the adult SN, the grafts contained also many nondopaminergic (GFP ${ }^{-}$) calbindin- and Girk2-expressing cells $(\boldsymbol{E}$, from dashed box in $\boldsymbol{D})$. Quantitative analysis $(\boldsymbol{J})$ showed that the peripheral regions of the graft contained significantly more Girk ${ }^{+} /$GFP $^{+}$cells and the central regions significantly more calbindin ${ }^{+} / \mathrm{GFP}^{+}$cells. Scale bars: $\boldsymbol{A}-\boldsymbol{D}$, $200 \mu \mathrm{m} ; \boldsymbol{F}-\mathbf{I}, 50 \mu \mathrm{m}$. Student's $t$ test, ${ }^{*} p<0.01 ; n=7$ for all groups.

also express TH (data not shown). Similarly, after transplantation of VM cells into either the intact or 6-OHDA-denervated neonatal rat striatum, $96.3 \pm 2.0 \%$ of $\mathrm{GFP}^{+}$cells were also $\mathrm{TH}^{+}$(Fig. $1 D-F)$. The vast majority of the $\mathrm{GFP}^{+}$cells also expressed the vesicular monoamine transporter (VMAT-2) (Fig. 1G-I). Immunohistochemistry for 5 -HT showed that the $\mathrm{VMAT}^{+} / \mathrm{GFP}^{-}$ cells in the grafts (red cells in $I$ ) were serotonergic neurons (data not shown). The few $\mathrm{GFP}^{+} / \mathrm{TH}^{-}$cells observed were typically immature looking and devoid of any dendritic processes (Fig. $1 \mathrm{~F}$, inset). The $\mathrm{GFP}^{+}$cells derived from the VM of this reporter mouse can therefore be used to reliably identify dopaminergic midbrain neurons.

Internal structure and DA neuron cell types in fetal VM grafts In both intact and 6-OHDA-lesioned hosts, the VM grafts contained two distinct $\mathrm{GFP}^{+}$cell populations with respect to position within the graft: located either in the center of the graft core or in the periphery at the graft-host interface (Fig. $2 A-F$ ). This pattern of cell distribution is characteristic for intrastriatal VM grafts of the size used here (Nikkhah et al., 1994). The cells within the center typically had a round, symmetrical morphology (Fig. 2B,E) and were smaller than those in the periphery, which had a more angular and elongated shape (Fig. 2C,F). This feature was particularly prominent in neonatal recipients (Fig. 2D-F) in which the separation between central and peripheral $\mathrm{GFP}^{+}$cells was more pronounced relative to what was seen in grafts placed in adults (Fig. 2A-C). Furthermore, cells in the periphery of grafts in neonatal hosts migrated further into the host parenchyma, giving the appearance of a greater degree of graft-host integration compared with the more distinct border formed by the graft-host interface in adult hosts. The dendritic processes emanating from the grafted $\mathrm{TH}^{+}$ neurons, moreover, were more elaborate and extended further into the host striatum in neonatal recipients.

In the midbrain of adult mice, two types of $\mathrm{TH}^{+}$neurons, similar to the ones seen in the intrastriatal VM grafts, can be distinguished based on size and shape, as well as position within the midbrain (Fig. $2 G-J)$. The smaller, rounded cells are distributed predominantly around the midline and throughout the VTA (particularly the more medioventral aspects), whereas the SNpc is mainly composed of larger, angular, and elongated cells. In both VM grafts and adult midbrain, $\mathrm{TH}^{+}$neurons differ significantly in size, with the more medial cells (VTA and graft center) being smaller than more laterally positioned cells (SNpc and graft periphery) (Fig. $2 \mathrm{~K}$ ).

Two subpopulations of $\mathrm{TH}^{+}$neurons can also be defined, in both the intact mouse midbrain and VM grafts, based on protein expression. In the midbrain, the distribution of calbindin and Girk2 within the dopaminergic neurons defines two primarily nonoverlapping populations (Fig. 3). A low-magnification overview shows that small, rounded calbindin ${ }^{+} / \mathrm{TH}^{+}$cells are distributed around the midline and within the VTA (Fig. $3 A-C$ ), whereas larger, angular Girk $2^{+} / \mathrm{TH}^{+}$cells are positioned more laterally, in the SNpc and within more lateral aspects of the VTA (Fig. 3D-F). One exception to this medial-calbindin/TH, lateral-Girk2/TH pattern is the lateral population of cells that make up the SN pars lateralis, which are predominately of the calbindin/TH subtype (Fig. $3 \mathrm{~V}$ ). There is also a small group of dorsal $\mathrm{SNpc} \mathrm{TH}^{+}$cells that are consistently found to be calbindin ${ }^{+}$and Girk ${ }^{-}$(Fig. $3 A, B$, dashed boxes). The remaining SNpc cells throughout the midbrain are overwhelmingly Girk $2^{+}$and calbindin ${ }^{-}$(Fig. 3iii,iv). Conversely, the more medial aspects of the VTA are composed of calbindin ${ }^{+} / \mathrm{TH}^{+}$cells and appear completely devoid of Girk $2^{+}$/ $\mathrm{TH}^{+}$cells (Fig. 3i). Based on the distribution of these two cells types, there is an overlap or "meshing" of VTA and SNpc around 
the medial lemniscus in which these regions intermingle, such that Girk ${ }^{+} / \mathrm{TH}^{+}$ cells extend from the SNpc into laterodorsal VTA (Fig. 3ii), and the calbindin ${ }^{+} /$ $\mathrm{TH}^{+}$cells of the VTA spill into medioventral SNpc (Fig. 3iii). Interestingly, the retrorubral (A8) cell group, located caudal to the $\mathrm{SN}$, contained both calbindin ${ }^{+} /$ $\mathrm{TH}^{+}$and Girk2 ${ }^{+} / \mathrm{TH}^{+}$neurons (data not shown), suggesting also that this caudal part of the mesencephalic DA cell system contains a mixture of the two cell types. The distribution of calbindin/ $\mathrm{TH}^{+}$and Girk2/ $\mathrm{TH}^{+}$cell types in the VTA and $\mathrm{SNpc}$ of the rat midbrain is identical to that described here for the mouse (data not shown).

In VM grafts from the TH-GFP mouse (Fig. 4), the Girk $2^{+} / \mathrm{GFP}^{+}$cells were found predominately in the periphery of the graft (Fig. $4 B, D$ ), whereas the calbindin ${ }^{+} / \mathrm{GFP}^{+}$cells were densely distributed within the core and scattered through the periphery (Fig. 4C,D). This is highlighted in high-magnification images (Fig. $4 F-I)$, incorporating a peripheral and more central aspect of the graft. Cell counting showed that the $\mathrm{GFP}^{+}$cells in the periphery of the graft were predominately of the Girk2 subtype and, conversely, that the calbindin ${ }^{+} / \mathrm{GFP}^{+}$subtype predominated in the center of the graft (Fig. $4 J$ ). Less than $5 \%$ of the $\mathrm{GFP}^{+}$ cells in the graft were positive for both Girk2 and calbindin. As was the case in the intact mouse mesencephalon (Fig. 3), there were also many nondopaminergic $\left(\mathrm{GFP}^{-}\right)$calbindin- and Girk2-expressing cells in the graft (Fig. 4E).

\section{Graft-derived innervation of the host brain in adult recipients}

One particular advantage of the GFP transgene is that it allows for a comparison of graft-derived, dopaminergic innervation of the host striatum in intact versus 6-OHDA-lesioned brains. Based on immunohistochemistry for GFP, the volume of graft-derived, dopaminergic fiber innervation was significantly $\sim 1$.7-fold greater in the striatum of lesioned relative to intact hosts (Fig. 5A-C). The volume occupied by the graft core itself, as delineated by the $\mathrm{GFP}^{+}$cell bodies, was not significantly different when comparing grafts placed in intact and lesioned hosts (Fig. 5C). The number of $\mathrm{GFP}^{+}$cell bodies was also not significantly different in intact $(6168 \pm 1064 ; 3.0 \pm 0.17 \%$ of total transplanted) compared with lesioned $(6996 \pm 338$; $3.5 \pm 0.53 \%$ ) hosts.

The GFP reporter also facilitates an assessment of graftderived dopaminergic axonal projections to structures outside of the striatum. As illustrated in schematic coronal sections (Fig. $5 D)$, graft-derived $\mathrm{GFP}^{+}$fibers could be found at relatively long
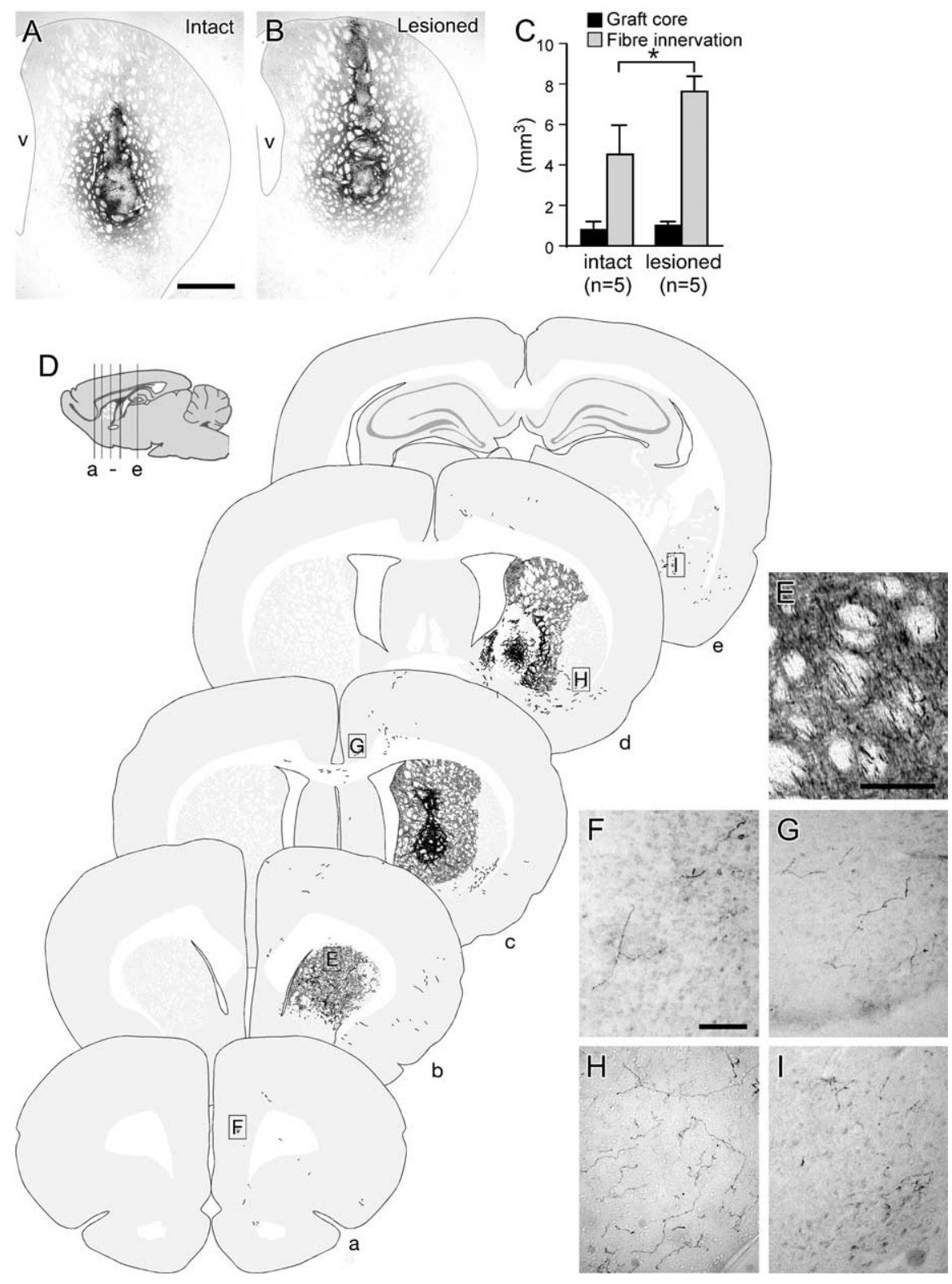

Figure 5. Graft-derived dopaminergic innervation of the forebrain in intact and denervated adult recipients. Six weeks after transplantation of E12.5 VM cells into the striatum of intact or 6-OHDA-lesioned adult rats, the graft-derived dopaminergic innervation of the host was assessed by GFP immunohistochemistry. The striatal volume innervated by the graft appeared consistently greater in lesioned $(\boldsymbol{B})$ relative to intact $(\boldsymbol{A})$ hosts, and formal quantification showed that this difference was significant ( $\boldsymbol{C}$, light gray bars). The volume of the graft core, as defined as the tissue occupied by GFP ${ }^{+}$cell bodies, was not significantly different in intact and lesioned hosts ( $\boldsymbol{C}$, black bars). $\boldsymbol{D}$ gives an overview of the distribution of graft-derived GFP ${ }^{+}$fibers, illustrated schematically in coronal sections $(\boldsymbol{a}-\boldsymbol{e})$ through one of the lesioned hosts, as indicated in the sagittal drawing. $\boldsymbol{E}-\boldsymbol{I}$ give photographic examples of graft-derived GFP ${ }^{+}$fibers in the striatal fiber bundles $(\boldsymbol{E})$, frontal cortex $(\boldsymbol{F}, \boldsymbol{G})$, ventrolateral striatum $(\boldsymbol{H})$, and the amygdala $(\boldsymbol{I})$. The locations from which these images were taken are indicated in $\boldsymbol{D}$. v, Ventricle. Scale bars: $\boldsymbol{A}, \boldsymbol{B}, 1$ $\mathrm{mm} ; \boldsymbol{E}, 100 \mu \mathrm{m} ; \boldsymbol{F}-\boldsymbol{I}, 100 \mu \mathrm{m}$. Student's t test, $\left.{ }^{*} p<0.01\right)$.

distances from the graft site in both a rostral and caudal direction. This pattern was consistent throughout both the lesioned and intact groups. Rostrally, $\mathrm{GFP}^{+}$fibers were observed coursing along the fiber bundles within the striatum (Fig. $5 E$ ) and extending through forceps minor into the frontal cortex. In all animals transplanted, scattered $\mathrm{GFP}^{+}$fibers could be found in frontal cortex (Fig. 5F) and more caudally, at approximately the same level as the graft, within the cingulate cortex (Fig. 5G). Fibers were also found traversing the corpus callosum into the contralateral hemisphere (data not shown, but see Fig. 5D, section c). Caudal 


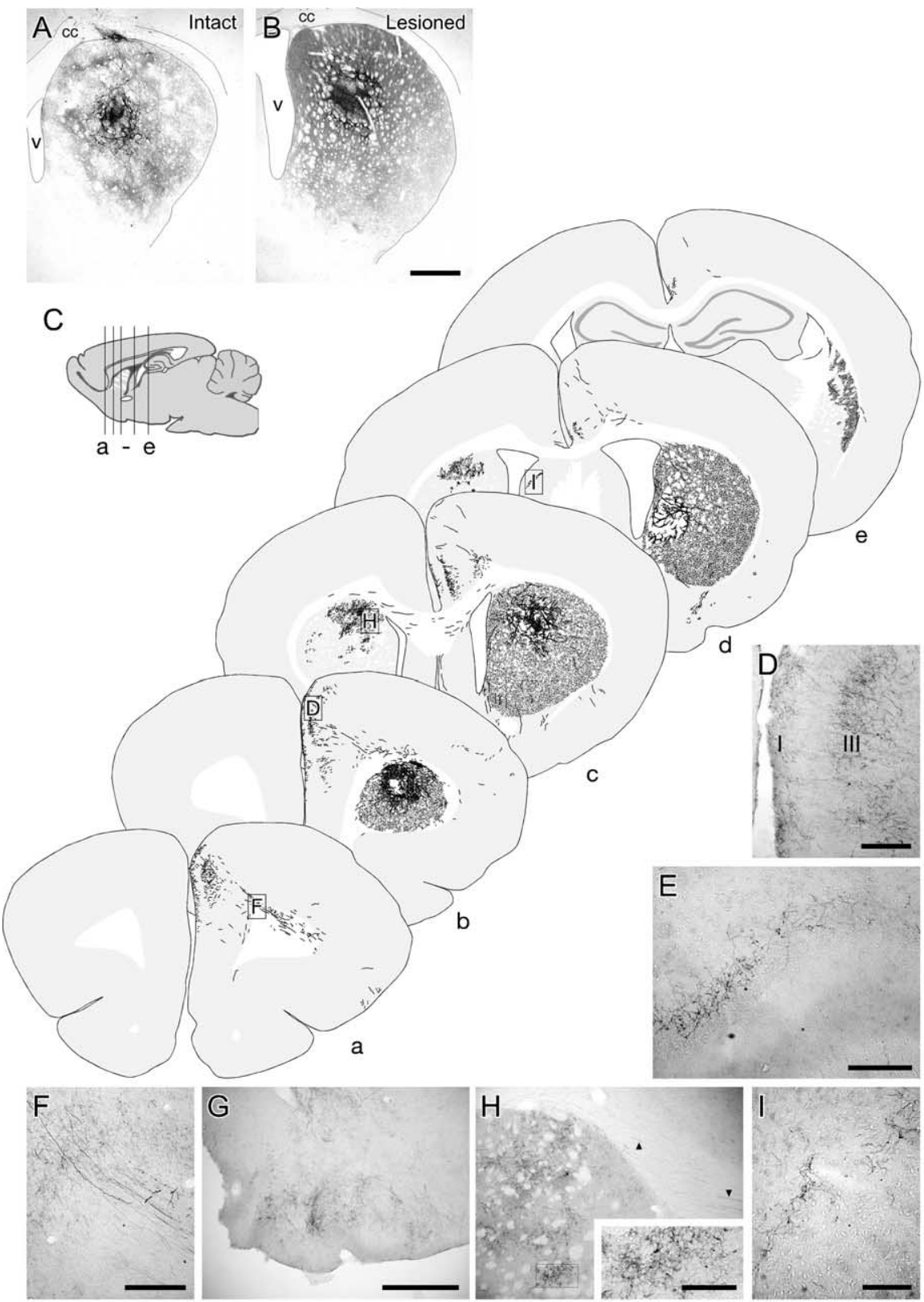

Figure 6. Graft-derived dopaminergic innervation of the forebrain after transplantation in intact and lesioned neonatal recipients. GFP immunohistochemistry 6 weeks after transplantation. In the intact striatum, certain areas were innervated more extensively than others, giving a prominent patchy appearance throughout the structure $(\boldsymbol{A})$. Innervation of the 6-0HDA-lesioned recipients was more extensive, resulting in a more homogenous fiber pattern throughout dorsal striatum ( $\boldsymbol{B})$. $\boldsymbol{C}$ gives an overview of GFP ${ }^{+}$fiber innervation throughout the brain, illustrated schematically in coronal sections $(\boldsymbol{a}-\boldsymbol{e})$ through one of the lesioned hosts, as indicated in the sagittal drawing. $\boldsymbol{D}-\boldsymbol{I}$, Photographic examples are also given of GFP ${ }^{+}$fibers in frontal cortex (D), piriform cortex $(\boldsymbol{E})$, forceps minor $(\boldsymbol{F})$, olfactory bulb $(\boldsymbol{G})$, contralateral striatum and corpus callosum $(\boldsymbol{H}$, boxed area shown at larger magnification as inset; arrowheads indicate GFP ${ }^{+}$fibers in corpus callosum), and contralateral septum (I). The locations from which these images are taken are indicated in $\mathbf{C}$. The image of GFP fibers in piriform cortex is taken from an animal in which the graft was placed quite ventrally, not represented in the schematic drawing. I, Cortex layer 1; III, cortex layer 3; v, ventricle. Scale bars: $\boldsymbol{A}, \boldsymbol{B}, 1 \mathrm{~mm} ; \boldsymbol{D}, \boldsymbol{E}, \boldsymbol{I}, 200 \mu \mathrm{m} ; \boldsymbol{F}, \boldsymbol{G}, 500 \mu \mathrm{m} ; \boldsymbol{H}$, inset, $100 \mu \mathrm{m}$.

to the graft, there was a consistent presence of thick $\mathrm{GFP}^{+}$processes in the ventrolateral striatum (Fig. $5 \mathrm{H}$ ) extending from the level of the graft as far back as the amygdaloid nuclei (Fig. 5I), a distance of $\sim 2.2 \mathrm{~mm}$ from the most caudal aspect of the graft core. In all animals, sparsely distributed $\mathrm{GFP}^{+}$fibers were also seen in the perirhinal cortex, apparently derived from fibers coursing through the anterior commissure (data not shown, but see Fig. $5 D$, sections d, e).

\section{Graft-derived dopaminergic innervation of the host brain in neonatal recipients}

In intact and lesioned neonates, the extent of $\mathrm{GFP}^{+}$fiber outgrowth from the VM grafts was assessed at 6 weeks, i.e., when the grafted animals had reached adulthood. The graft-derived, dopaminergic innervation of the host striatum, as assessed by GFP immunohistochemistry, was clearly much more extensive than that seen for grafts placed in adult striatum (compare Figs. $5 A, B, 6 A, B$ ). In intact neonates (Fig. $6 A$ ), some areas were innervated more densely than others, giving a prominent "patchy" appearance throughout the striatum. In contrast, in 6-OHDAlesioned neonates (Fig. 6B), the graftderived innervation was more homogenous and extended throughout the entire dorsal striatum to a degree approaching that seen for endogenous dopaminergic innervation of the striatum in intact adult rats.

A striking feature of grafts placed in neonates was the degree of graft-derived innervation of structures outside of the striatum. The schematic coronal sections in Figure 6 give an overview of the extent of $\mathrm{GFP}^{+}$fiber outgrowth seen in a representative case, typical of that seen in both intact and lesioned animals. Of particular note, there was a robust and consistent innervation of frontal cortex in a layerspecific manner (Fig. 6D), apparently derived from fibers coursing through the forceps minor (Fig. 6F). Caudally, graftderived fibers could be found in the amygdala, perirhinal cortex, and the contralateral septum (data not shown and Fig. 6I). In one animal, in which the graft was placed more ventrally, there was also innervation of the piriform cortex (Fig. 6E) and, in some cases, also in the olfactory bulb (Fig. 6G). At the level of the graft, $\mathrm{GFP}^{+}$fibers were found in several animals coursing through the corpus callosum and extending into the contralateral striatum (Fig. 6H)

\section{Retrograde tracing from striatum or frontal cortex identifies different subsets of dopaminergic neurons in VM grafts}

One group of lesioned neonates, grafted with wild-type VM tissue, received 6 weeks later an injection of the CTB for retrograde tracing of axonal connections from either the dorsolateral striatum or the frontal cortex. One week later, grafted $\mathrm{TH}^{+}$cells were found to incorporate the CTB tracer after injection at either site. The distribution of CTB-labeled cells within the graft was dramatically different, however, depending on the delivery site. In animals in which the CTB was placed in the dorsolateral striatum, the CTBlabeled cells were almost exclusively located in the periphery of 
the graft (Fig. $7 A-D$, arrowheads). The majority of these cells were $\mathrm{TH}^{+}$; however, there were also a number of $\mathrm{CTB}^{+} /$ $\mathrm{TH}^{-}$cells (Fig. $7 E-H$ ). The rare $\mathrm{CTB}^{+}$ cells seen closer to the center of the graft core were also $\mathrm{TH}^{-}$(data not shown). Many of the $\mathrm{CTB}^{+} / \mathrm{TH}^{+}$cells expressed the Girk2 protein and were of the large, angular morphology (Fig. 7C,D and $G, H$ ). Figure $7, I$ and $J$, shows the fluorescent signal associated with the CTB tracer at the injection point in the striatum and at the level of the graft. It is important to note that the CTB toxin itself did not reach the graft through passive diffusion.

In animals with CTB injections into the frontal cortex (Fig. 8I), the majority of $\mathrm{CTB}^{+} / \mathrm{TH}^{+}$cells were consistently located in the center of the graft (Fig. $8 A-D$, arrowheads), with some few scattered $\mathrm{CTB}^{+} / \mathrm{TH}^{+}$cells in the periphery (data not shown). Most of these cells were of the small, rounded type and expressed calbindin (Fig. 8C,D and $G, H$ ). Although most of the CTB-labeled cells were $\mathrm{TH}^{+}$, there was also a significant proportion of $\mathrm{CTB}^{+} / \mathrm{TH}^{-}$cells both in the center and the periphery of the grafts (see example in Fig. $8 E-H)$.

\section{Discussion}

We show here that the $\mathrm{TH}^{+}$cells in intrastriatal VM grafts can be distinguished as two major subtypes: (1) a small, rounded cell type, with an average diameter of $\sim 13$ $\mu \mathrm{m}$, most of which are located in the central core of the graft and express calbindin, and (2) a large, angular and elongated cell type, with an average mean diameter of $\sim 19 \mu \mathrm{m}$, which is located in the periphery of the grafts and express Girk2. These characteristics match well with the two principal $\mathrm{TH}^{+}$cell types in adult mouse VM: the small calbindin ${ }^{+}$cells in the VTA and the medial aspect of the SNpc, and the larger, angular Girk2 ${ }^{+}$cells in the SNpc. These distinctive features (morphology, location, and Girk2/calbindin expression) thus seem to be retained after transplantation and can be used to distinguish the $\mathrm{SNpc}$ and VTA subtypes in intrastriatal VM grafts. Similar observations have been reported recently by Mendez et al. (2005) in grafts of human VM tissue.

In the VM grafts derived from the TH-GFP transgenic mouse, GFP was expressed in the vast majority of the grafted $\mathrm{TH}^{+}$neurons. The reporter protein was expressed not only in the cell bodies but also throughout the axonal and dendritic processes, which made it possible to trace the projections from the grafted DA neurons in their entirety. In rats lesioned and grafted as neonates, GFP immunostaining showed extensive innervation not only of the striatum, as reported previously (Snyder-Keller et al., 1989; Herman et al., 1991; Abrous et al., 1993; Costantini et al.,
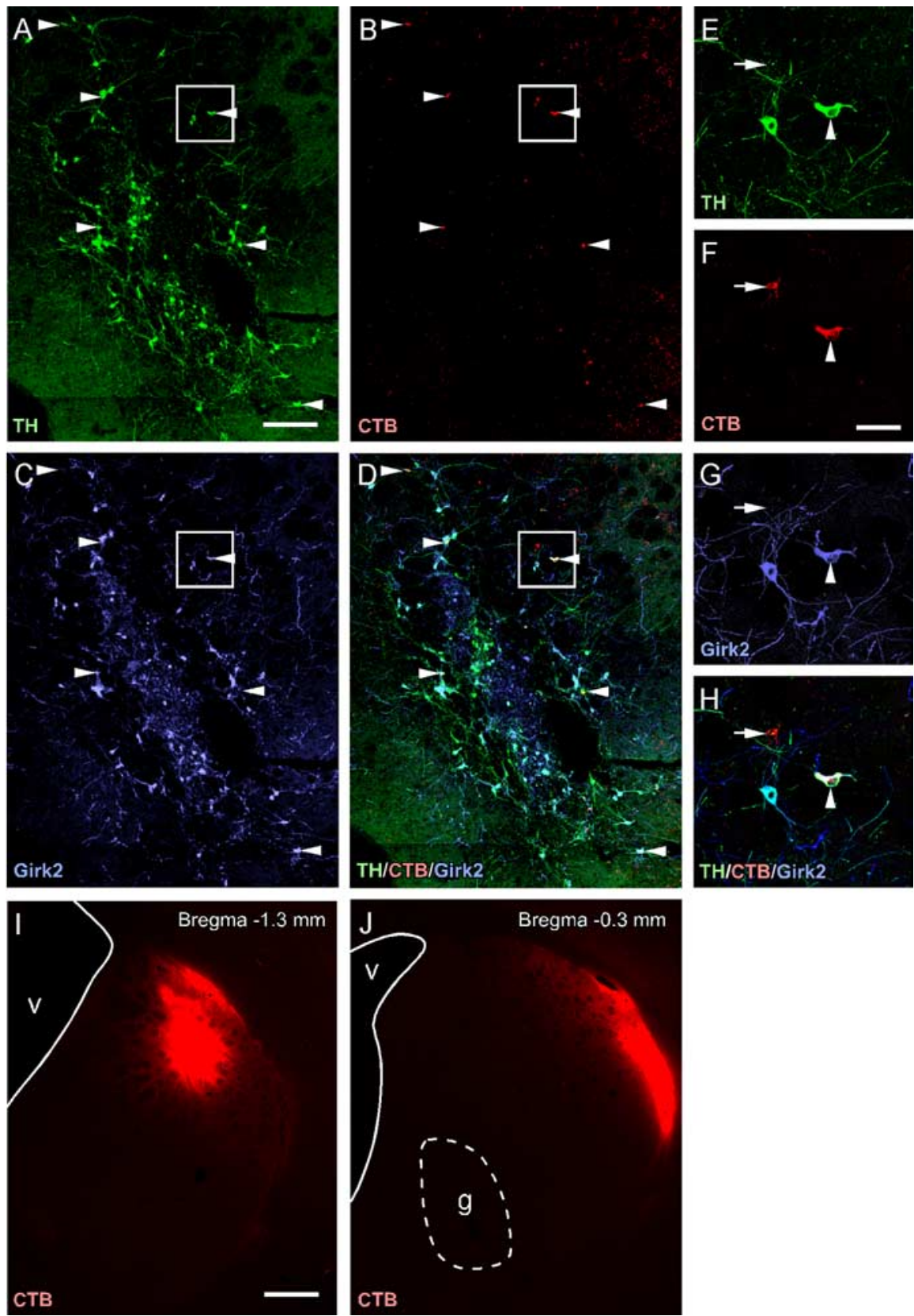

Figure 7. Retrograde tracing from dorsolateral striatum in VM grafted neonates. Six weeks after transplantation of wild-type VM tissue in 6-OHDA-lesioned neonates, CTB prelabeled with an Alexa-555 fluorophore was injected into the dorsolateral striatum. Immunohistochemistry for TH $(\boldsymbol{A})$ and Girk2 $(\boldsymbol{C})$ shows that many retrogradely labeled CTB ${ }^{+}$cells $(\boldsymbol{B})$ in the VM grafts expressed both of these proteins $(\boldsymbol{D})$. Arrowheads in $\boldsymbol{A}-\boldsymbol{D}$ identify the dopaminergic $\left(\mathrm{TH}^{+}\right)$cells that had incorporated the $\mathrm{CTB}$ tracer, located in the periphery of the graft. The boxed area is shown at higher magnification $(\boldsymbol{E}-\boldsymbol{H})$. In addition to $\mathrm{TH}^{+}$cells (arrowhead), the CTB tracer was taken up by a number of $\mathrm{TH}^{-}$cells (arrow) lying within the VM grafts $(\boldsymbol{E}-\boldsymbol{H})$. CTB staining resulting from passive diffusion of the tracer is illustrated at the injection site in the dorsolateral striatum $(I)$ and at the level of the graft $(J) . g$, Graft; $v$, ventricle. Scale bars: $A-D, 200 \mu \mathrm{m} ; \boldsymbol{E}-\boldsymbol{H}, 50 \mu \mathrm{m} ; \boldsymbol{I}, \boldsymbol{J}, 500 \mu \mathrm{m}$.

1994), but also of the frontal, cingulate, and perirhinal cortices, as well as parts of the limbic system. Although some of these extrastriatal graft projections were observed also in animals grafted as adults, they were much less extensive. Another difference between grafts implanted in neonatal or adult recipients was the degree of integration between graft and host. In neonatal hosts, the $\mathrm{TH}^{+}$cells in the periphery of the graft (i.e., the SNpc type) had migrated further into the host striatal parenchyma, which resulted in a more pronounced separation between the central VTA-like cell type and the peripheral SNpc cells. This more ac- 

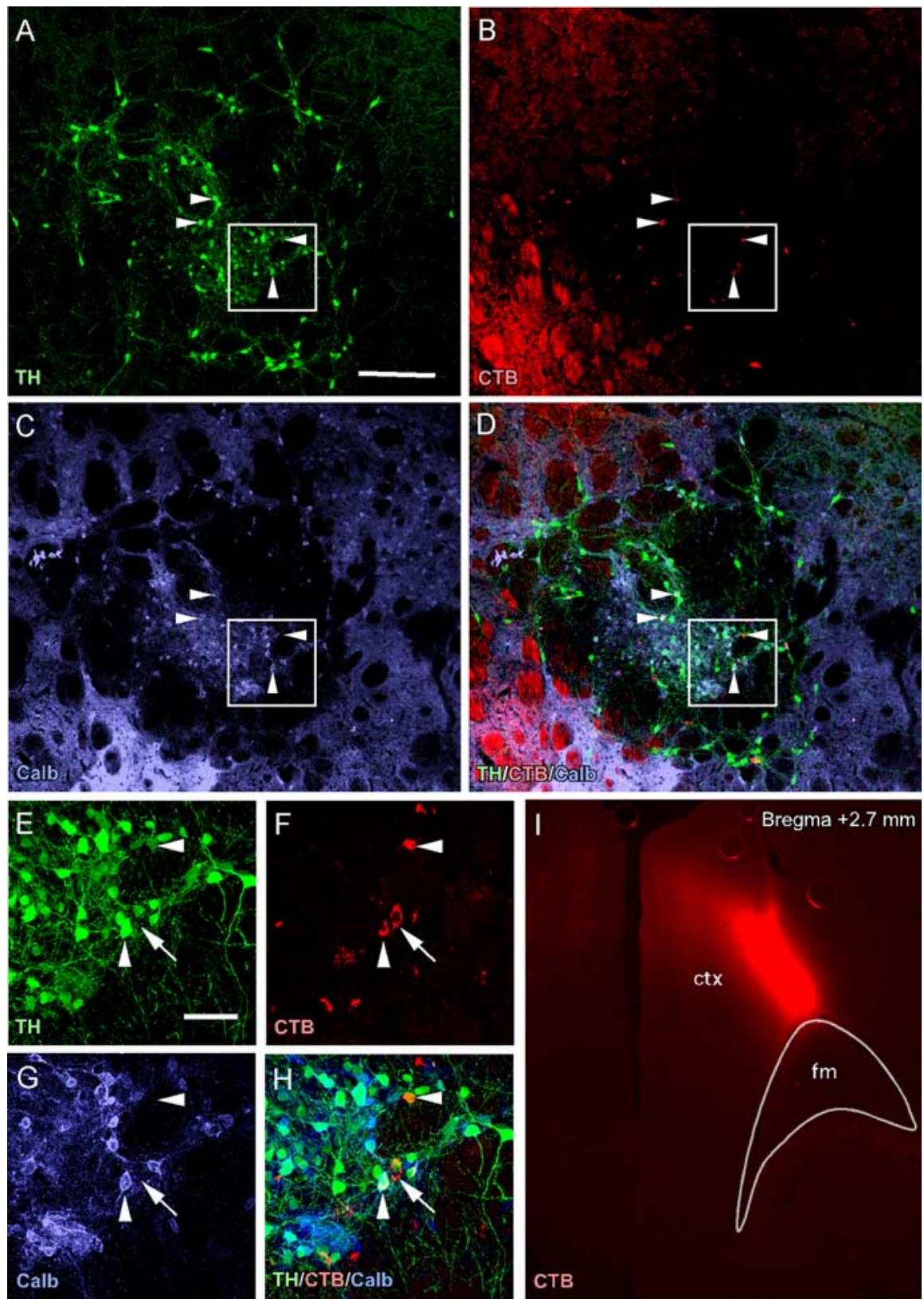

Figure 8. Retrograde tracing from frontal cortex in VM-grafted neonates. Six weeks after transplantation of wild-type VM tissue into 6-OHDA-lesioned neonates, (TB prelabeled with an Alexa-555 fluorophore was injected into the frontal cortex. Immunohistochemistry for TH $(\boldsymbol{A})$ and calbindin $\left(\boldsymbol{C}\right.$; Calb) shows that many retrogradely labeled $\mathrm{CTB}^{+}$cells $(\boldsymbol{B})$ in the VM grafts expressed both of these proteins $(\boldsymbol{D})$. Arrowheads in $\boldsymbol{A}-\boldsymbol{D}$ identify the dopaminergic $\left(\mathrm{TH}^{+}\right)$cells that had incorporated the $\mathrm{CTB}$ tracer, within the center of the graft. The prominent $\mathrm{CTB}^{+}$signal in the bottom left corner of $B$ represents $\mathrm{CTB}^{+}$thalamocortical projections coursing through striatal fiber bundles. Boxed areas in $\boldsymbol{A}-\boldsymbol{D}$ are shown at higher magnification in $\boldsymbol{E}-\boldsymbol{H}$. In addition to $\mathrm{TH}^{+}$cells (arrowheads), the CTB tracer was taken up by a number of $\mathrm{TH}^{-}$cells (arrow) within the VM grafts $(\boldsymbol{E}-\boldsymbol{H})$. CTB staining resulting from passive diffusion of the tracer is illustrated at the injection site in the frontal cortex $(I)$. ctx, Cortex; fm, forceps minor. Scale bars: $\boldsymbol{A}-\boldsymbol{D}, 200 \mu \mathrm{m} ; \boldsymbol{E}-\boldsymbol{H}, 50 \mu \mathrm{m} ; \boldsymbol{I}, 500 \mu \mathrm{m}$.

centuated separation between VTA and SNpc cell types in neonatal graft recipients provided an additional advantage in the retrograde tracing experiments.

In the retrograde tracing experiment, small $(0.2-1 \mu \mathrm{l})$ injections of fluorophore-labeled CTB were made into the two major target areas of the $\mathrm{TH}^{+}$axonal projections from the VM grafts, i.e., the striatum and frontal cortex. The results show that the peripheral, Girk ${ }^{+} \mathrm{SNpc}$ cell type was preferentially labeled from injections in striatum, and the central, calbindin ${ }^{+}$VTA cell type was preferentially labeled from injections in the frontal cortex.
This provides evidence that axonal outgrowth from the two cell types is differentially regulated. Both cell types are clearly able to extend axons for long distances in the host brain, but they project to different forebrain regions, suggesting that they respond differently to cues present in the denervated targets. The axons from the grafted SNpc neurons ramified extensively in the striatal gray matter, i.e., in the tissue immediately surrounding the graft. In contrast, axons derived from the VTA cells grew straight through the striatum, apparently along the myelinated fiber bundles and the forceps minor, into the frontal cortex in which they ramified to form a terminal network in distinct cortical layers. These data show that the regulation of axonal growth from grafted DA neurons is quite specific and suggest the presence of axon guidance and/or target recognition molecules in the 6-OHDA-lesioned forebrains that can act to guide the growing axons from the grafted SNpc and VTA neurons to their appropriate targets. The fact that the extent of fiber outgrowth was greatly increased in the 6-OHDA-lesioned animals compared with nonlesioned recipients is in line with this view, suggesting that the level or availability of these growth-regulation molecular cues may increase after removal of the host DA afferents.

Previous studies have shown that axonal outgrowth from transplanted immature postmitotic neurons or neuroblasts is quite precisely regulated by the host target, both with respect to the total extent of fiber outgrowth and the innervation patterns formed by the newly formed terminal networks (Bjorklund et al., 1990; Wictorin et al., 1991; Isacson and Deacon, 1996; Olsson et al., 1997; Kirik et al., 2001). These differences are observed not only when comparing the axonal outgrowth from different types of grafted neurons (differing with respect to their transmitter phenotype) but also between subtypes of neurons using the same neurotransmitter, such as different subtypes of cholinergic neurons transplanted to the hippocampus (Nilsson et al., 1988; Clarke et al., 1990) or different subtypes of serotonergic neurons transplanted to striatum or spinal cord (Foster et al., 1985; Foster et al., 1988). This holds true for different types of dopaminergic neurons, as shown by the present data comparing fiber outgrowth from different subtypes of mesencephalic DA neurons and those of Zuddas et al. (1991) and Hudson et al. (1994) comparing the extent of fiber outgrowth from diencephalic and mesencephalic DA neurons. The mechanisms underlying this neuron-specific growth regulation in the postnatal or adult CNS are poorly known. In many cases, the innervation status of the grafted target region, i.e., the presence or absence of 
the corresponding intrinsic afferent innervation, has been shown to have a marked and sometimes decisive influence. Studies in hippocampus, for example, have shown that the extension of axons from grafted fetal septal cholinergic neurons into the hippocampus is blocked by the presence of an intact septal cholinergic innervation (Bjorklund et al., 1979, 1990). A similar effect, albeit somewhat less pronounced, is seen in the striatum and cortex after removal of the host DA afferents (Doucet et al., 1989; Kirik et al., 2001; present data). Both diffusible growthpromoting factors and membrane- or substrate-bound axon growth-regulating molecules have been implicated in this response. Studies in 6-OHDA-lesioned rats have suggested that the production of diffusible growth-stimulating factors in the striatum is increased after removal of the intrinsic DA afferents (Carvey et al., 1996) and that both BDNF and glial cell line-derived neurotrophic factor may be involved in this lesion-induced growth response (Zhou et al., 1996; Yurek and Fletcher-Turner, 2001). Signaling through membrane-bound receptor-ligand interactions between axonal growth cones and surrounding cells is also known to play a role in regulating neuronal fiber growth. Yue et al. (1999) have reported that signaling through the Eph family receptor EphB1 and ligand Epherin-B2 may differentially regulate axon guidance of A9 and A10 mesencephalon DA neurons during development of the nigrostriatal pathway. Similarly, Lin et al. (2005) have reported recently that neuritic outgrowth in VM cultures is influenced by signaling through netrin-1 and slit proteins and their respective receptors, deleted in colorectal cancer and robol and robo2, and also that these factors are differentially expressed by different dopaminergic neuron subtypes identified by calbindin and Girk2 expression.

The present findings have important implications for the current efforts to generate DA neurons from stem cells or immature neural progenitors for transplantation in PD. Because grafted DA neurons are likely to exert their main functional effects via DA release from the axon terminal network formed in the host striatum, only DA neurons that have the capacity to reinnervate the denervated striatum will be therapeutically useful. Of the DA neuron types investigated so far, only the SNpc subtype appear to possess this capacity. As emphasized previously by us (Lindvall and Bjorklund, 2004) and other investigators (Bjorklund et al., 2002), this implies that neurons used for cell replacement in PD not only have to be dopaminergic but they should be of the correct, nigral phenotype. Fetal VM tissue used for grafting in $\mathrm{PD}$ contains a mixture of the SNpc and VTA subtypes. In case the relative proportions and/or survival of the two cell types varies from case to case, which seems quite likely, this factor may contribute to the variable outcome seen in VM-transplanted PD patients (for review, see Lindvall and Bjorklund, 2004). TH immunostaining, which is commonly used to monitor DA neuron survival in VM grafts, does not provide any distinction between the two subtypes and may thus be misleading: VM neuron grafts rich in $\mathrm{TH}^{+}$neurons may not be functional unless they contain a substantial proportion of the correct $\mathrm{SNpc}$ subtype combined with an extensive, dense graft-derived $\mathrm{TH}^{+}$terminal network in the host striatum. In studies of dopaminergic neurons derived from embryonic stem (ES) cells, transplanted to the striatum of 6-OHDA-lesioned rats, the grafts have been seen to contain large numbers of $\mathrm{TH}^{+}$cells, but the associated $\mathrm{TH}^{+}$fiber outgrowth has been quite limited (Lee et al., 2000; Bjorklund et al., 2002; Ben-Hur et al., 2004; Perrier et al., 2004). This mismatch between the abundance of $\mathrm{TH}^{+}$cells in the graft and the sparse innervation of the host striatum suggest that only a small fraction of the
ES cell-derived DA neurons are of the correct, fully mature nigral phenotype.

\section{References}

Abercrombie M (1946) Estimation of nuclear population from microtome sections. Anat Rec 94:239-247.

Abrous DN, Manier M, Mennicken F, Feuerstein C, Le Moal M, Herman JP (1993) Intrastriatal transplants of embryonic dopaminergic neurons counteract the increase of striatal enkephalin immunostaining but not serotoninergic sprouting elicited by a neonatal lesion of the nigrostriatal dopaminergic pathway. Eur J Neurosci 5:128-136.

Abrous N, Guy J, Vigny A, Calas A, Le Moal M, Herman JP (1988) Development of intracerebral dopaminergic grafts: a combined immunohistochemical and autoradiographic study of its time course and environmental influences. J Comp Neurol 273:26-41.

Ben-Hur T, Idelson M, Khaner H, Pera M, Reinhartz E, Itzik A, Reubinoff BE (2004) Transplantation of human embryonic stem cell-derived neural progenitors improves behavioral deficit in Parkinsonian rats. Stem Cells 22:1246-1255.

Bjorklund A, Lindvall O (1984) Dopamine-containing systems in the CNS. In: Handbook of chemical neuroanatomy (Bjorklund A, Hokfelt T, eds), pp 55-122. Amsterdam: Elsevier.

Bjorklund A, Kromer LF, Stenevi U (1979) Cholinergic reinnervation of the rat hippocampus by septal implants is stimulated by perforant path lesion. Brain Res 173:57-64.

Bjorklund A, Nilsson OG, Kalen P (1990) Reafferentation of the subcortically denervated hippocampus as a model for transplant-induced functional recovery in the CNS. Prog Brain Res 83:411-426.

Bjorklund LM, Isacson O (2002) Regulation of dopamine cell type and transmitter function in fetal and stem cell transplantation for Parkinson's disease. Prog Brain Res 138:411-420.

Bjorklund LM, Sanchez-Pernaute R, Chung S, Andersson T, Chen IY, McNaught KS, Brownell AL, Jenkins BG, Wahlestedt C, Kim KS, Isacson O (2002) Embryonic stem cells develop into functional dopaminergic neurons after transplantation in a Parkinson rat model. Proc Natl Acad Sci USA 99:2344-2349.

Carvey PM, Lin DH, Faselis CJ, Notermann JK, Ling ZD (1996) Loss of striatal DA innervation increases striatal trophic activity directed at DA neurons in culture. Exp Neurol 140:184-197.

Cavalieri B (1966) Geometria degli indivisibli, pp 1-320. Torino, Italy: Unione Typographico-Editrice.

Clarke DJ, Nilsson OG, Brundin P, Bjorklund A (1990) Synaptic connections formed by grafts of different types of cholinergic neurons in the host hippocampus. Exp Neurol 107:11-22.

Costantini LC, Vozza BM, Snyder-Keller AM (1994) Enhanced efficacy of nigral-striatal cotransplants in bilaterally dopamine-depleted rats: an anatomical and behavioral analysis. Exp Neurol 127:219-231.

Dahlstrom A, Fuxe K (1964) Evidence for the existence of monoaminecontaining neurons in the central nervous system. I. Demonstration of monoamines in the cell bodies of brain stem neurons. Acta Physiol Scand 62 [Suppl 232]:231-255.

Damier P, Hirsch EC, Agid Y, Graybiel AM (1999) The substantia nigra of the human brain. I. Nigrosomes and the nigral matrix, a compartmental organization based on calbindin $\mathrm{D}(28 \mathrm{~K})$ immunohistochemistry. Brain 122:1421-1436.

Doucet G, Brundin P, Seth S, Murata Y, Strecker RE, Triarhou LC, Ghetti B, Bjorklund A (1989) Degeneration and graft-induced restoration of dopamine innervation in the weaver mouse neostriatum: a quantitative radioautographic study of $\left[{ }^{3} \mathrm{H}\right]$ dopamine uptake. Exp Brain Res 77:552-568.

Dunnett SB, Björklund A (1992) Staging and dissection of rat embryos. In: Neural transplantation. A practical approach. (Dunnnet SB, Björklund A, eds), pp 1-18. Oxford: Oxford UP.

Dunnett SB, Björklund A (2000) Dissecting embryonic neural tissues for transplantation. In: Neuromethods: cell and tissue transplantation in the CNS (Dunnett SB, Boulton AA, Baker GB, eds), pp 3-25. Totowa, NJ: Humana.

Foster GA, Schultzberg M, Gage FH, Bjorklund A, Hokfelt T, Nornes H, Cuello AC, Verhofstad AA, Visser TJ (1985) Transmitter expression and morphological development of embryonic medullary and mesencephalic raphe neurones after transplantation to the adult rat central nervous system. I. Grafts to the spinal cord. Exp Brain Res 60:427-444. 
Foster GA, Schultzberg M, Gage FH, Bjorklund A, Hokfelt T, Cuello AC, Verhofstad AA, Visser TJ, Emson PC (1988) Transmitter expression and morphological development of embryonic medullary and mesencephalic raphe neurones after transplantation to the adult rat central nervous system. III. Grafts to the striatum. Exp Brain Res 70:242-255.

Haque NS, LeBlanc CJ, Isacson O (1997) Differential dissection of the rat E16 ventral mesencephalon and survival and reinnervation of the 6-OHDA-lesioned striatum by a subset of aldehyde dehydrogenasepositive TH neurons. Cell Transplant 6:239-248.

Herman JP, Abrous DN, Le Moal M (1991) Anatomical and behavioral comparison of unilateral dopamine-rich grafts implanted into the striatum of neonatal and adult rats. Neuroscience 40:465-475.

Hudson JL, Bickford P, Johansson M, Hoffer BJ, Stromberg I (1994) Target and neurotransmitter specificity of fetal central nervous system transplants: importance for functional reinnervation. J Neurosci 14:283-290.

Inanobe A, Yoshimoto Y, Horio Y, Morishige KI, Hibino H, Matsumoto S, Tokunaga Y, Maeda T, Hata Y, Takai Y, Kurachi Y (1999) Characterization of G-protein-gated $\mathrm{K}^{+}$channels composed of Kir3.2 subunits in dopaminergic neurons of the substantia nigra. J Neurosci 19:1006-1017.

Isacson O, Deacon TW (1996) Specific axon guidance factors persist in the adult brain as demonstrated by pig neuroblasts transplanted to the rat. Neuroscience 75:827-837.

Kirik D, Winkler C, Bjorklund A (2001) Growth and functional efficacy of intrastriatal nigral transplants depend on the extent of nigrostriatal degeneration. J Neurosci 21:2889-2896.

Lee SH, Lumelsky N, Studer L, Auerbach JM, McKay RD (2000) Efficient generation of midbrain and hindbrain neurons from mouse embryonic stem cells. Nat Biotechnol 18:675-679.

Liang CL, Sinton CM, German DC (1996) Midbrain dopaminergic neurons in the mouse: co-localization with calbindin-D28K and calretinin. Neuroscience 75:523-533.

Lin L, Rao Y, Isacson O (2005) Netrin-1 and slit-2 regulate and direct neurite growth of ventral midbrain dopaminergic neurons. Mol Cell Neurosci 28:547-555.

Lindvall O, Bjorklund A (2004) Cell therapy in Parkinson's disease. Neurorx 1:382-393.

McRitchie DA, Hardman CD, Halliday GM (1996) Cytoarchitectural distribution of calcium binding proteins in midbrain dopaminergic regions of rats and humans. J Comp Neurol 364:121-150.

Mendez I, Sanchez-Pernaute R, Cooper O, Vinuela A, Ferrari D, Bjorklund L, Dagher A, Isacson O (2005) Cell type analysis of functional fetal dopamine cell suspension transplants in striatum and substantia nigra of patients with Parkinson's disease. Brain, in press.

Nikkhah G, Olsson M, Eberhard J, Bentlage C, Cunningham MG, Bjorklund A (1994) A microtransplantation approach for cell suspension grafting in the rat Parkinson model: a detailed account of the methodology. Neuroscience 63:57-72.

Nikkhah G, Winkler C, Rödter A, Samii M (2000) Microtransplantation of nigral dopamine neurons: a "step by step" recipe. In: Neuromethods: cell and tissue transplantation in the CNS (Dunnett SB, Boulton AA, Baker GB, eds), pp 207-231. Totowa, NJ: Humana.
Nilsson OG, Clarke DJ, Brundin P, Bjorklund A (1988) Comparison of growth and reinnervation properties of cholinergic neurons from different brain regions grafted to the hippocampus. J Comp Neurol 268:204-222.

Olsson M, Bentlage C, Wictorin K, Campbell K, Bjorklund A (1997) Extensive migration and target innervation by striatal precursors after grafting into the neonatal striatum. Neuroscience 79:57-78.

Perrier AL, Tabar V, Barberi T, Rubio ME, Bruses J, Topf N, Harrison NL, Studer L (2004) Derivation of midbrain dopamine neurons from human embryonic stem cells. Proc Natl Acad Sci USA 101:12543-12548.

Peterson D, A. (1999) The use of fluorescent probes in cell counting procedures. In: Quantitative methods in neuroscience-a neuroanatomical approach (Janson AM, Evans SM, Möller A, eds). Oxford: Oxford UP.

Rogers JH (1992) Immunohistochemical markers in rat brain: colocalization of calretinin and calbindin-D28k with tyrosine hydroxylase. Brain Res 587:203-210.

Sawamoto K, Nakao N, Kobayashi K, Matsushita N, Takahashi H, Kakishita K, Yamamoto A, Yoshizaki T, Terashima T, Murakami F, Itakura T, Okano H (2001) Visualization, direct isolation, and transplantation of midbrain dopaminergic neurons. Proc Natl Acad Sci USA 98:6423-6428.

Schein JC, Hunter DD, Roffler-Tarlov S (1998) Girk2 expression in the ventral midbrain, cerebellum, and olfactory bulb and its relationship to the murine mutation weaver. Dev Biol 204:432-450.

Schultzberg M, Dunnett SB, Bjorklund A, Stenevi U, Hokfelt T, Dockray GJ, Goldstein M (1984) Dopamine and cholecystokinin immunoreactive neurons in mesencephalic grafts reinnervating the neostriatum: evidence for selective growth regulation. Neuroscience 12:17-32.

Snyder-Keller AM, Carder RK, Lund RD (1989) Development of dopamine innervation and turning behavior in dopamine-depleted infant rats receiving unilateral nigral transplants. Neuroscience 30:779-794.

Wictorin K, Lagenaur CF, Lund RD, Bjorklund A (1991) Efferent projections to the host brain from intrastriatal striatal mouse-to-rat grafts: time course and tissue-type specificity as revealed by a mouse specific neuronal marker. Eur J Neurosci 3:86-101.

Winkler C, Kirik D, Bjorklund A, Dunnett SB (2000) Transplantation in the rat model of Parkinson's disease: ectopic versus homotopic graft placement. Prog Brain Res 127:233-265.

Yue Y, Widmer DA, Halladay AK, Cerretti DP, Wagner GC, Dreyer JL, Zhou R (1999) Specification of distinct dopaminergic neural pathways: roles of the Eph family receptor EphB1 and ligand ephrin-B2. J Neurosci 19:2090-2101.

Yurek DM, Fletcher-Turner A (2001) Differential expression of GDNF, BDNF, and NT-3 in the aging nigrostriatal system following a neurotoxic lesion. Brain Res 891:228-235.

Zhou J, Pliego-Rivero B, Bradford HF, Stern GM (1996) The BDNF content of postnatal and adult rat brain: the effects of 6-hydroxydopamine lesions in adult brain. Brain Res Dev Brain Res 97:297-303.

Zuddas A, Corsini GU, Barker JL, Kopin IJ, Di Porzio U (1991) Specific reinnervation of lesioned mouse striatum by grafted mesencephalic dopaminergic neurons. Eur J Neurosci 3:72-85. 